\title{
História e Civismo na Roma Liviana
}

\author{
Marinalva Vilar de LIMA ${ }^{*}$ \\ Michelly Pereira de Sousa CORDÃO••
}

\begin{abstract}
Resumo: O artigo focaliza a maneira como Tito Lívio (sécs. I a.C. I d.C.) articula política, civismo e cotidiano em sua $A b$ urbe condita libri, através da análise das representações sociais que constrói. Discute a noção de história enquanto mimesis de um passado presentificado por Lívio nos primórdios do Império. Apresenta um Lívio construtor de uma memória da sociedade romana que retroage às épocas da realeza e da república romanas. Da ênfase conferida por Lívio a algumas dessas práticas (cerimônias e crenças religiosas, ritos funerários, relações familiares, valores sociais, disputas de poder, etc.), resultou nossa compreensão de que a política constitui o fio articulador de sua escritura. Conceito que em Lívio engloba as práticas cívicas/públicas realizadas pelos cives no espaço da urbs a partir do respeito aos valores da civitas.
\end{abstract}

Palavras-chave: Historiografia latina; Tito Lívio; História; Exemplum.

Para Tito Lívio, em nossa percepção, o exercício por excelência da política se constituía das práticas civis dos romanos, realizadas no interior da urbe romana. Distingue as

- Professora Doutora da Unidade Acadêmica de História e Geografia Centro de Humanidades - Universidade Federal de Campina Grande UFCG - 58109-900 - Campina Grande - PB - Brasil.

E-mail: iramlima@ig.com.br

- Mestranda em História - Professora Substituta - Unidade Acadêmica de História e Geografia - Centro de Humanidades - Universidade Federal de Campina Grande - UFCG - 58109-900 - Campina Grande PB - Brasil. E-mail: michellycordao@gmail.com 
ações ${(\text { artes })^{1}}$ no espaço de sua pátria $(\text { domi })^{2}$ dos empreendimentos militares (militae) $)^{3}$, acrescentando-lhes as maneiras de viver (vitae), os costumes (mores) e os perfis dos homens (virae) ${ }^{4}$; elementos que, juntos, teriam contribuído para a ascensão universal de Roma $^{5}$ e que são tomados por Lívio como eixos norteadores de sua escritura.

Escreve uma "história cívica" que assim pode ser designada por rememorar as coisas que aconteceram no universo da civitas $^{6}$ romana e que foram empreendidas pelos cidadãos romanos (os cives). As narrativas dos empreendimentos militares são apresentadas por Lívio como extensão do que era promovido em Roma, com ênfase para o caráter dos romanos nas guerras, pois que os feitos "puros", nelas empreendidos, não foram vistos por ele como tendo maior relevância. Idéia já presente em Cícero que ensina ao orador como ele deve usar a história em seus discursos:

(...) não se fale só dos feitos dos próprios homens, mas, com relação aos que se distinguem pela reputação e pelo nome, também da vida e do caráter de cada um (CÍ́CERO apud HARTOG, 2001: 151).

É a rememoração dos feitos de Roma, enquanto instância cívica, que enfeixa a escrita da história de Lívio. "História cívica" marcada pelas artes, pelos mores e pelas vitae dos cidadãos romanos por excelência. Seu interesse era, enfim, escrever uma história da vida e dos costumes dos romanos. Narrativa que focaliza as práticas da tradição e as atitudes que dessas se desviavam. Age como um historiador que necessita dá conta, tanto de exemplos a serem imitados, como a serem rejeitados e, assim, com um conjunto de quadros de ações exemplares é que Lívio preenche cada volumen de sua obra.

Aqui, optamos pelo conceito de "civismo" liviano, em detrimento da noção de política, por percebê-lo mais condizente com o universo cultural de compreensão romana, 
visto que contempla as variadas representações sociais da Roma antiga que constituem a $A b$ urbe condita libri.

O civismo serve a Lívio como eixo articulador para as narrativas que constrói das práticas religiosas às decisões tomadas nas assembléias públicas; dos prantos em honra dos mortos aos comícios durante as eleições consulares. Do universo temático do corpus liviano, sobressaem uma multiplicidade de representações: práticas e crenças religiosas, atitudes diante da morte (ritos funerários), relações familiares, a exemplo do casamento, valores sociais (moralismo e patriotismo), imagens do feminino, disputas por poder. Elas evidenciam a preocupação do historiador em contemplar as experiências cívicas que constituíam o "cotidiano" do ambiente social do qual fazia parte e para quem endereçou sua obra: a aristocracia.

Escrita que projeta a edificação de modelos cívicos para os quais seus contemporâneos deveriam direcionar o olhar e a eles promover eco sonante no cenário da Roma augustana. Com esse intuito elabora uma obra que retroage aos tempos de fundação da cidade e vai até o início da era imperial, tomando os modelos de uirtus como fios de ligação. Eixo discursivo articulado com tamanha força retórica que leva o leitor moderno a perder de vista as perspectivas espaço-temporal a que destina grande importância.

É, por exemplo, em meio a um momento de grande turbulência da história romana, à época republicana, em que a ameaça do retorno eminente de mais um enfrentamento entre Roma e Véios, cidade com quem já há tempos era alimentada uma antiga contenda, que Lívio localiza a entrada em cena de Marco Fúrio Camilo. Situação discursiva em que Lívio articula, em um mesmo homem, grandeza de liderança e respeito à tradição religiosa no cumprimento de seu próprio destino e, por conseguinte, dos destinos de Véios e de Roma. Cidades cujos destinos se cruzam, necessariamente, pela via da oposição: "Assim se deu a queda de Véios, uma das mais opulentas cidades etruscas, cuja grandeza se evidenciou mesmo em sua última derrota" (TITO LÍVIO, livro V, cap. 18). Camilo, típico político que representa uma gens tradicional de Roma, nos é apresentado por 
Tito Lívio em muitos outros momentos de perturbações cívicas a que sua uirtus poderia vir a pôr fim. Em um desses momentos, ele também é apresentado em completa consonância com as atitudes de devoção das matronas, dadas a conhecer por Lívio como mantenedoras da purificação da cidade, conforme descrição que faz da situação e da participação dessas:

As mães de família, que o pânico generalizado arrancara de suas casas, faziam súplicas nos templos e dirigiam preces aos deuses para que afastassem a desgraça de suas casas, dos templos, das muralhas, e que fizessem recair sobre Véios aquela ameaça, uma vez que as cerimônias religiosas haviam sido restabelecidas em conformidade com os ritos, e os prodígios, expiados (TITO LÍVIO, livro V, cap. 18).

A edificação de valores que Lívio enxerga enquanto relegados ao desuso por seus contemporâneos é o que, ao nosso ver, tonifica as muitas narrativas que constrói em sua interferência no passado, fazendo (re)empregos e deslocamentos de histórias conservadas pela tradição na costura discursiva que cinge para seus contemporâneos. Discurso que resulta de cortes, escolhas e recusas de modelos de comportamentos e costumes, adotados pelos ancestrais romanos desses que vivem a Roma augustana.

É para os cidadãos de uma Roma expandida ${ }^{7}$, com graves dificuldades em manter os fios de ligação entre mundos extremamente distintos, que Lívio endereça uma escritura que pretende fazer eco, não apenas no centro do império, mas até onde se diga existir Roma.

A respeito dessa Roma da experiência escriturística e histórica de Tito Lívio, cabe lembrar do movimento restaurador enfeixado por Otávio Augusto (GRIMAL, 1997). Princeps que se impôs no cenário da história de Roma, pondo em prática um projeto político que marcou os mais distintos universos da vida romana do início do império. Sua habilidade política lhe permitiu visualizar a necessidade de estabelecer uma articulação entre 
mundo temporal e espiritual, chegando a creditar seu poder ao desígnio dos deuses.

Sobre a participação, ou identificação, de Tito Lívio com os rumos dados pela política augustana para a cidade, Grimal considera que: "Tito Lívio, sem dúvida, servia Augusto, mas apenas na medida em que este servia essa pátria profundamente amada" (GRIMAL, 1997: 78). Portanto, sonante com os ideais restauradores da época augustana, Lívio faz vir à tona uma Roma que se encontra encoberta, guardada em um passado que a tradição conservou. $O$ discurso liviano apresenta-se sonante com a produção discursiva levada a efeito pelo círculo literário patrocinado pelo aristocrata Mecenas (GRIMAL, 1997).

É uma Roma cadaverizada que Tito Lívio pretende preencher com os tecidos, músculos, articulações, vasos, artérias e sangue que localiza como sobreviventes no mimetismo da tradição. Escritura que intenta, tanto quanto em um Heródoto, por exemplo, dar o estatuto de revificadora da experiência, ainda que de forma e para objetivos diferentes. Se para Heródoto há como preocupação maior com a elaboração de uma memória que impeça o esquecimento dos feitos do passado, para Lívio o esforço de mimetismo tem uma intencionalidade didáticopedagógica, visto que pretende trazer à cena experiências de romanos - constituidores das gentes tradicionais - que tiveram como preocupação maior a manutenção da civitas, colocando-a acima de seus interesses pessoais.

Retomando o exemplo de Marco Fúrio Camilo, Lívio o apresenta quase como um deus após a vitória ensejada sobre Véios. Todas as ordens sociais, em grande multidão, comemoravam seu esplendoroso triunfo:

A chegada do ditador foi festejada por todas as ordens, que lhe foram ao encontro, uma multidão como nunca se vira antes para qualquer de seus antecessores. O triunfo ultrapassou em esplendor tudo o que se costumava ver em tais manifestações. Quando Camilo entrou na cidade em seu carro puxado por cavalos brancos, todos os olhares se voltaram para ele. Não 
parecia um simples cidadão, nem mesmo um ser humano, diziase. Rivalizando com Júpiter e com o Sol, o ditador despertava os escrúpulos religiosos. Por isso, esse triunfo foi mais brilhante que bem acolhido.

Em seguida, Camilo designou um local no Aventino para o templo de Juno Rainha, consagrou o de Mater Matuta e, após ter concluído esses ritos sagrados e profanos, abdicou da ditadura (TITO LÍVIO, livro V, cap. 23).

Ideal personalístico que Lívio objetiva incutir em seus leitores, procurando encarnar modelos de civismo mimetizados pela tradição, bem como, cuidando para respeitá-la apenas naquilo que vem a corroborar sua intencionalidade.

A história, como experiência passível de ser recuperada em benefício de épocas póstumas, já anunciada por Isócrates (apud HARTOG, 2001: 14), é o que foi ensejado por Lívio, na medida em que retornou ao passado para trazer de lá experiências que pudessem ensinar, educar, remodelar as maneiras das pessoas se relacionarem com o presente. Percepção que, conforme análise de Hartog, remonta à experiência helênica - de Atenas do declínio da polis, momento em que se passou a invocar o passado enquanto tempo a ser imitado. " $E$ daí que o tema da história como fornecedora de exemplos irá tomar seu impulso duradouro" (HARTOG, 2001: 14).

Se Lívio anuncia seu ideário em uma Roma pós-crise, provocada pela guerra civil do século II a.C., que resultou na instalação do modelo político em que três cidadãos compartilhavam a experiência do governo (I triunvirato e II triunvirato), o faz dialogando com uma tradição helênica por ele deslocada em favor de seus intentos cívicos.

A título de síntese, considerando a obra de Lívio em seu conjunto, é possível perceber que ele estabeleceu uma escritura em que apresenta os primeiros anos da formação de Roma (o período dos reis), para em seguida apresentar à larga os anos de consolidação do modelo Institucional Romano (o período Republicano), seguidos da narrativa do início do império, até 9 a.C. A prosa liviana assume um caráter de anais, afastando-se 
dos prosadores que optavam por recortes mais pontuais e definidos, narrando uma guerra ou acontecimento específico. Sua narrativa do passado apresenta-se em clara conexão com o presente, articulação que reconhece e reivindica ${ }^{8}$.

É a imagem de uma Roma em um momento de decadência dos valores humanos, que Lívio enxerga enquanto espelho para onde o destino da cidade reflexionou. Situação que serve de palco para a polifonia interpretativa com que pretende admoestar seus contemporâneos. Ergue-se enquanto voz que pretende recolocar a cidade no destino que a ela cabe, através de uma escrita prenhe de exempla que lhe alcança e a que suas representações imprimem um efeito de anamnesis que põe ao alcance de seus contemporâneos. Se aos indivíduos (de épocas que distam no tempo) estabelece um lugar de importância, o faz na medida em que suas ações permitam-lhe - a Lívio - colocar em cena situações de que faz uso pedagógico, tanto por sua grandeza de realização, quanto por sua ruptura com o ideal de uirtus.

A escritura liviana nos permite acompanhar, didaticamente, as muitas façanhas de um ideal de ser romano que Lívio registra como tendo existido na Roma dos tempos da realeza e da República, mais contundentemente nesta segunda.

Tito Lívio regressa a momentos da história romana em que, diante das situações postas, os romanos se autopreterem em favor da defesa de Roma. Movimento escriturístico que fala de um outro lugar para o qual desloca as memórias exemplares registradas pela tradição. Relação narrativa que repete argumentos dos historiadores que lhe antecederam, bem como, os questiona, os (des)constrói.

É sobre e para uma Roma que coloca acima das vontades individuais que Lívio fala e está a serviço enquanto partícipe do projeto restaurador do princeps, mas, antes de tudo, edificador de uirtus, defensor da civitas. Fórmula que desenvolve a partir do estabelecimento de uma constante conexão entre as experiências que narra do passado e as possibilidades de verificação no presente, visto que se preocupa com as 
MARINALVA VILAR DE LIMA E MICHELLY P. DE SOUSA CORDÃO

reminiscências que alcançam sua época, como se pode depreender nos excertos que seguem:

Ainda hoje, quando se trata de votar leis ou nomear magistrados, os senadores conservam esse direito, que todavia constitui mera formalidade. São convocados a dar sua aprovação antes das eleições, quando ainda são conhecidos os resultados. (...)

Houve, assim, um ano de interregno entre dois reinados, donde o nome de interregno usado ainda em nossos dias (TITO LÍVIO, livro I, cap. 17).

Tito Lívio traduz o passado para seus contemporâneos recorrendo a situações, costumes, lugares, práticas que afirmam os exempla a que recorre para a edificação cívica de sua época. Movimento escriturístico para que faz uso, mesmo recorrente, da dimensão religiosa. Evoca a lembrança de um tempo em que diz ser o universo cheio de sinais divinos. Um tempo em que as aves sobrevoavam os ares e seus gestos eram entendidos pelos humanos como uma mensagem dos deuses, a quem não poderiam desobedecer:

Ao chegarem ao Janículo, estava Lucumão na carruagem ao lado da mulher quando viu uma águia descer rapidamente e, adejando sobre sua cabeça, arrebatar-lhe o chapéu. A ave continuou a sobrevoar a carruagem com grandes gritos. Como se cumprisse uma missão divina, recolocou-o exatamente em sua cabeça, voando depois para as alturas (TITO LÍVIO, livro I, cap. 34).

Tempo ainda em que os deuses apareciam em sonhos, anunciando sinais por meio dos quais enviavam suas mensagens aos homens:

Diz-se que enquanto dormiam os dois cônsules tiveram a mesma visão: um homem de estatura e imponência sobre-humanas apareceu e disse-lhes que um dos generais e um dos exércitos 
eram devidos aos deuses manes e à mãe Terra. $\mathrm{O}$ exército cujo general tivesse sacrificado aos manes as legiões inimigas e, em seguida, se sacrificado a si próprio, daria a vitória a seu povo e a sua pátria (TITO LÍVIO, livro VIII, cap. 6).

Aviso a que os homens convinham seguir e, por isso, os dois cônsules decidem que o primeiro exército que fosse impulsionado a ceder pelo inimigo, faria o sacrifício, junto com seu comandante. Assim, Lívio faz a descrição do ritual, que antecede a morte do cônsul Décio em meio às fileiras inimigas. Ao repetir a fala do pontífice, Décio conversa com uma multidão de deuses que afloram do texto de Lívio:

O pontífice ordenou-lhe que vestisse a toga pretexta, e com a cabeça velada, a mão saindo debaixo da toga e levantada até o queixo, os pés sobre um dardo estendido no chão, dissesse: 'Jano, Júpiter e Marte, pai dos romanos; Quirino e Belona e Lares, divindades Novensiles, deuses Indígetes, deuses que tendes em vossas mãos a sorte dos romanos e a de seus inimigos, e vós, deuses Manes, eu vos conjuro, eu vos suplico respeitosamente, vos peço a graça e nela confio de que concedais força e vitória ao povo romano dos quirites ${ }^{9}$, e insinueis nos inimigos do povo romano dos quirites o terror, o pânico e a morte. Como declarei por minhas palavras, sacrifico-me pela república, pelo exército, pelas legiões, pelos auxiliares do povo romano dos quirites e ofereço juntamente comigo as legiões e os auxiliares do inimigo aos deuses Manes e à Terra' (TITO LÍVIO, livro VIII, cap. 9).

Para Lívio, esse tipo de prática, em que um jovem romano se sacrificava pela república, estava praticamente fora do campo do possível em seu tempo. Em sua época, eram os vícios que caracterizavam as práticas dos romanos, contaminando o aspecto "verdadeiramente" virtuoso, que Lívio, considerando-o histórico, localizou nos tempos mais recuados da cidade. Afirma que a memória dos costumes desses tempos encontra-se esquecida em seu presente, constatação que lhe impulsiona a lutar contra seu completo esquecimento: 
MARINALVA VILAR DE LIMA E MICHELLY P. DE SOUSA CORDÃO

Embora haja desaparecido a lembrança [memoria] de nossos costumes civis e religiosos, pela preferência outorgada aos costumes novos e estrangeiros em detrimento das velhas instituições ancestrais, julguei que não me afastaria do tema de minha obra ao mencionar essas tradições nos próprios termos em que nos foram transmitidas e enunciadas (TITO LÍVIO, livro VIII, cap. 11).

Lívio rememora um período em que os senadores costumavam reunir a juventude romana e, com ela, formar imensos exércitos:

Hoje, em caso de invasão estrangeira, não seria fácil recrutar um exército igual àquele, nem sequer reunindo as forças do império romano que, apesar disso, o universo mal pode conter, de tal modo crescemos apenas naquilo que nos prejudica: riqueza e luxo (TITO LÍVIO, livro VII, cap. 25).

Era um tempo em que todos celebravam com alegria as vitórias dos romanos, direcionando ações de graças aos deuses e respeitando os decretos do senado (TITO LÍVIO, livro X, cap. 21).

No entanto, Lívio admite que mesmo nos primeiros séculos da república já havia manipulação dos auspícios para se justificar falsamente a guerra:

(...) embora os frangos não comessem, o pulário ousou mentir sobre os auspícios e comunicou ao cônsul que os frangos mostravam um apetite muito favorável. O cônsul, contente, anuncia publicamente que os auspícios são excelentes, que os deuses aprovam essa luta e faz arvorar o sinal do combate (TITO LÍVIO, livro X, cap. 40).

Contudo, nesse mesmo período ainda era possível encontrar cônsules, cuja honestidade informava suas práticas de tal modo que chegavam a castigar quem manipulasse os 
augúrios, embora eles pudessem ser beneficiados com isso. É o exemplum de Lúcio Papírio Cursor que, sendo informado sobre tal fato, ordena que os pulários, responsáveis pela leitura dos augúrios retirados dos frangos, fossem dispostos na primeira fila da batalha. Assim, provavelmente morreriam e a ira divina seria a culpada e não o cônsul:

Antes que se erguesse o grito de guerra e os adversários corressem um para o outro, um dardo lançado ao acaso atingiu um dos pulários, que caiu na primeira fila" (TITO LÍVIO, livro X, cap. 40).

Castigo necessário para os que descumpriam o ideal da uirtus e que aparece na narrativa como sendo obra de um Acaso que também age pro pátria.

Cada vez mais, a harmonia dos tempos de outrora vai se esvaindo por completo. Por defendê-la como eixo de orientação para a civitas de seu tempo, é que Lívio constrói a memória do que lhe é inverso. Assim, torna claro para seus leitores que esses atos do passado não devem ser imitados, pois que foram eles que, com o passar dos tempos, conduziram Roma à situação terrificante do séc. I a.C. que, por sua vez, estaria sendo suavizada pela política levada a cabo por Augusto. Lívio elabora uma leitura do passado em diálogo com um tempo marcado por fortes disputas de poder e, ao mesmo tempo, se propõe a influenciá-lo, acalmando-o a partir de exemplos a serem rejeitados.

Os prazeres, resultado do vício que eram as paixões, deveriam ser reprimidos, segundo Lívio, cabendo ao homem conseguir se conter em face da libido. As ações públicas pro pátria serviriam como elemento de auxílio para que os romanos refreassem seus desejos e vícios. Daí sua preocupação em construir uma memória para elas na contraposição com esses.

Lívio narrou tanto as guerras externas, promovidas pelos romanos, quanto suas ações civis; no entanto, a essas últimas atribuiu maior relevância, por percebê-las como artérias de 
sustentação da projeção de Roma para além da Península itálica. Compreendemos que considera o exercício das virtudes cívicas ou o seu desvirtuamento enquanto balizas da grandeza/decadência de Roma. Disso resultando que a defesa da pátria passava, prioritariamente, pela manutenção da civitas.

\section{Referências Bibliográficas}

ARAÚJO, O. L. de, LIMA, M. V. de (orgs.). Ensaios em Estudos Clássicos. Campina Grande-PB: Editora da UFCG, 2006, 293 p.

ARENDT, H. Entre o passado e o futuro. $3^{\mathrm{a}}$ ed. Trad.: Mauro W. Barbosa de Almeida, São Paulo: Perspectiva, 1992.

CANDOU, J. Anthropologie de la mémoire. Paris: PUF, 1996.

CANDOU, J. Memoire et identité. Paris: PUF, 1998.

CÂNFORA, L. Júlio César: o ditador democrático. Trad: Antônio da Silveira Mendonça, São Paulo: Estação liberdade, 2002, 508p.

CORASSIN, M. L. Sociedade e política na Roma Antiga. São Paulo: Atual, 2001, $128 \mathrm{p}$.

ERNOUT, A; MEILLET, A. Dictionnaire étymologique de la langue latine: histoire des mots. Paris: Librairie C. Klincksieck, 1932, $1108 \mathrm{p}$.

GRIMAL, P. A civilização romana. Trad.: Isabel St. Aubyn, Lisboa: Edições 70, 1993, 354 p.

GRIMAL, P. O século de augusto, trad.: Rui Miguel O. Duarte, Lisboa: Edições 70, 1997, $111 \mathrm{p}$.

HADAS, M. Livy as scripture. The American Journal of Philology, v. 61, pp. 445-456, 1940. Disponível em <http://www.jstor.org $>$. Acesso em 26/01/2008.

HARTOG, F. A história de Homero a Santo Agostinho. Trad.: Jacyntho Lins Brandão. Belo Horizonte: UFMG, 2001, 288 p.

HARTOG, F. O espelho de Heródoto: ensaio sobre a representação do outro. Trad.: Jacyntho Lins Brandão, Belo Horizonte: Ed. UFMG, 1999, $474 \mathrm{p}$.

HARTOG, F. Os antigos, o passado e o presente. Trad.: Sonia Lacerda et al. Brasília: Ed. UnB, 2003, 204 p.

KOSELLECK, R. Futuro e Passado: contribuições à semântica dos tempos históricos. Trad.: Wilma Patrícia Mas e Carlos Almeida Pereira, Rio de Janeiro: Contraponto; EDPUC, 2006, 364 p. 
MELLOR, R. The roman historians. New York/London: Routledge, 1999, $212 \mathrm{p}$.

MILES, G. B. The cycle of Roman History in Livy's First Pentad. The American Journal of Philology, v. 107, pp. 1-33, 1986. Disponível em $<$ http://www.jstor.org > . Acesso em 26/01/2008.

MOMIGLIANO, A. As raízes clássicas da historiografia moderna. Trad.: Maria Beatriz Florenzano, São Paulo: EDUSC, 2004, 226 p.

PETIT, P. A paz romana. Trad.: João Pedro Mendes, São Paulo: Pioneira; EDUSP, 1989, $350 \mathrm{p}$.

SYME, R. Livy and Augustus. Havard Studies in Classical Philology, v. 64, pp. 27-87, 1959. Disponível em < http://www.jstor.org > . Acesso em 26/01/2008.

VASALY, A. Personality and power: Livy's depiction of the Appii Claudii in the First Pentad. Transactions of the American Philological Association, v. 117, pp. 203-226, 1987. Disponível em < http://www.jstor.org >. Acesso em 26/01/2008.

\section{FONTES}

CICERÓN. El orador. Trad.: E. Sánchez Salor. Madrid: Alianza Editorial, 2004, $150 \mathrm{p}$.

CÍCERO, M. T. Dos deveres. Trad.: Angélica Chiapeta. São Paulo: Martins Fontes, 1999, $217 \mathrm{p}$.

TITO LÍVIO. História de Roma. Trad.: Paulo Matos Peixoto. São Paulo: Paumape, 1989 (6 vols.).

LIVY. Livy, with an English traduction in fourteen volumes. Trad.: B. O. Foster. Cambridge, Massachusets, \& London, William Heinemann. Harward University Press, v. V, books XXI-XXII, 1929 (Loeb Classical Library).

TITE-LIVE. Histoire Romaine (tome I, livre I). Texto estabelecido por J. Bayet e traduzido por G. Baillet, Paris: Les Belles Lettres.

TITO LÍVIO. Historia de Roma desde su fundación. Trad.: José Antônio Villar Vidal. Madrid-ES: Editorial Gredos, 1990 (Biblioteca Clásica Gredos). 
LIMA, Marinalva Vilar de; CORDÃO, Michelly Pereira de Sousa. History and Good Citizenship in Livian Rome. História, v.28, n.2, p.605-620, 2009.

\begin{abstract}
This article focuses on the way in which Titus Livius (1BC - 1AD) presented politics, good citizenship and everyday life in his $A b$ urbe condita libri, through an analysis of the social representations that he constructed. It argues the conception of history as a mimesis of a past offered by Livid in the beginnings of the Empire. It presents Livid as a constructor of a memory of the Roman society that modified the times of royalty and of the Roman republic. The emphasis given by Livius to some of these practices (ceremonies and religious beliefs, funeral rites, family relations, social values, power disputes etc.) resulted in our understanding that politics constituted the line of thinking in his writing. It can be assessed that Livius includes civic or public practices exercised by cives in the space of the urbs respecting the values of the civitas.
\end{abstract}

Keywords: Latin historiography; Titus Livius; History; Exemplum.

\title{
NOTAS
}

${ }^{1}$ Plural de ars: modo se ser ou de agir. Há outros significados, mas aqui, nos interessou apenas esse por estar de acordo com o que entendemos querer dizer Lívio ao usar o termo. Veja: ERNOUT, A; MEILLET, A. Dictionnaire étymologique de la langue latine: histoire des mots. Paris: Librairie C. Klincksieck, 1932, p. 72.

2 Plural de domus: "casa". Por oposição à peregri, foris e militae. Simboliza a família. Dos derivados e compostos, tem-se: domesticus: "doméstico, familiar". De onde: "privado, nacional". (Idem, ibidem, p. 270). Trata-se, no texto de Lívio, das ações realizadas no espaço da cidade por excelência: Roma. Embora, ao incorporar novos territórios ao Estado romano, os estadistas atribuíssem a seus homens o status de cidadãos, não significa que esses fossem considerados "homens romanos" de fato. Pois que, para sê-lo, exigia-se toda uma formação cívica específica ao espaço de Roma. Formação que se baseava na 
HISTÓRIA E CIVISMO NA ROMA LIVIANA

prática das virtudes tradicionais e dos deveres que conferiam a um homem ser, de fato, chamado civis [membro livre de uma cidade, a qual pertence por sua origem ou por adoção, cidadão livre (Idem, ibidem, p. 185). Sobre os deveres tipicamente romanos, veja: CÍCERO, Marco Túlio. Dos deveres. Trad.: Angélica Chiapeta. São Paulo: Martins Fontes, 1999.

${ }^{3}$ Plural de milita ("serviço militar", de onde: "campanha"), termo que deriva de miles, "soldado" (ERNOUT, A; MEILLET, A. op.cit. p. 582). No caso do texto de Lívio, trata-se das ações empreendidas no exterior do espaço da urbs.

${ }^{4}$ Plural de uir: "homem", por oposição à mulher. Exprime as qualidades viris ou masculinas do homem. Por seqüência: marido, homem digno desse nome, herói. Tomou o sentido de soldado, pois que as atividades na guerra eram exclusivas aos homens (Idem, ibidem, p. 1.069).

${ }^{5}$ TITO LÍVIO. História de Roma. Trad.: Paulo Matos Peixoto. São Paulo: Paumape, 1989, prefácio, p. 18. Ressalte-se que todas as citações da obra de Tito Lívio foram retiradas da tradução de Paulo Matos Peixoto. Além dessa tradução, foram consultados os textos da Biblioteca Gredos e Belles Lettres.

6 Derivado abstrato de civis, "condição de cidadão", "conjunto de cidadãos". Por seqüência, "cerco de um governo, cidade, Estado". Daí, com a passagem ao sentido concreto, sinônimo de urbs, por oposição ao campo. Traduz a pólis e a politéia. Na língua de direito, civicus (civil, cívico) opõe-se a militaris. Assim, urbs se refere ao espaço concreto de Roma, ao passo que civitas, tem a ver com os elementos "abstratos" daquela: suas leis e costumes. São a esses que Lívio dá ênfase em sua obra, valorizando, pois, a civitas. Veja: ERNOUT, A; MEILLET, A. op.cit. p. 185.

7 Acerca dos movimentos de expansão territorial, das conquistas realizadas pelos romanos e para outras informações sobre a sociedade romana de fins da república e da época imperial, aqui veiculadas, consultar: PETIT, P. A paz romana. Trad.: João Pedro Mendes, São Paulo: Pioneira; EDUSP, 1989, 350 p.; CORASSIN, M. L. Sociedade e política na Roma Antiga. São Paulo: Atual, 2001, 128 p.; CANFORA, L. Júlio César: o ditador democrático. Trad: Antônio da Silveira Mendonça, São Paulo: Estação liberdade, 2002; GRIMAL, P. A civilização romana. Trad.: Isabel St. Aubyn, Lisboa: Edições 70, 1993, 354 p.; GRIMAL, P. O século de augusto, trad.: Rui Miguel O. Duarte, Lisboa: Edições 70, 1997, $111 \mathrm{p}$.

HISTÓRIA, São Paulo, 28 (2): 2009 
${ }^{8}$ Idem, ibidem, p.18.

9 Lívio assim designa os cidadãos por excelência romanos, para distingui-los dos estrangeiros: os plebeus.

Artigo recebido em 03/2009. Aprovado em 08/2009. 